\title{
UNDERSTANDING ASIAN EMERGING STOCK MARKETS
}

\author{
Shaista Arshad ${ }^{1}$, Omair Haroon², Syed Aun R. Rizvi ${ }^{3}$ \\ ${ }^{1}$ University of Nottingham Malaysia Campus, Semenyih, Malaysia. Email: \\ Shaista.arshad@nottingham.edu.my \\ ${ }^{2}$ Suleman Dawood School of Business, Lahore University of Management Science, Lahore, \\ Pakistan. Email: Omair.haroon@lums.edu.pk \\ ${ }^{3}$ Corresponding Author, Suleman Dawood School of Business, Lahore University of Management \\ Sciences, Lahore, Pakistan. Email: Aun@rizvis.net; aun.raza@lums.edu.pk
}

\begin{abstract}
We use a three-step process employing multifractal detrended fluctuation analysis to study time-varying changes in the volatility and efficiency of Asian emerging equity markets. Our findings suggest that, in emerging markets, long-term stability and efficiency are linked to market development and liberalization. Our findings further suggest that financial crises have a negative impact on the efficiency of emerging markets but only in the short term.
\end{abstract}

Keywords: Efficiency; Asia; Emerging markets; Equity market; Volatility. JEL Classifications: C22; E44; G1.

Article history:

Received : July 1, 2018

Revised : October 8, 2018

Accepted : : December 11, 2018

Available online : January 31, 2019

https://doi.org/10.21098/bemp.v0i0.983 


\section{INTRODUCTION}

In this paper, we analyse time-varying changes in the efficiency and volatility of the Asian emerging stock markets to understand their behaviour during periods of financial stability and instability. The interlinkages between stock markets and economic growth are well established in the finance and economic growth literature. The main conclusion of this literature is that a well-functioning stock market spurs economic growth (Luintel and Khan, 1999; Bell and Rousseau, 2001; Campos, Karanasos, and Tan, 2012; Narayan and Narayan, 2013; Mishra and Narayan, 2015). Stock markets are important because they provide much needed capital and liquidity to fuel faster capital accumulation, productivity improvement, and improved economic efficiency via effective resource allocation (Atje and Jovanovic, 1993; Levine and Zervos, 1993, 1998; Rousseau and Wachtel, 2000; Caporale, Howells and Soliman, 2004; Beck and Levine, 2005).

Rapid globalization coupled with the easing of economic and investment barriers has resulted in new markets typically classified as emerging markets. It is argued that the increasing linkages between countries brought about by financial integration often cause capital flows into emerging markets to become highly volatile (Gua and Huang, 2010; Menkhoff, Sarno, Schmelling, and Shrimpf, 2012; McKinnon, 2013). However, at the same time, emerging markets have become more attractive to foreign investors for diversification purposes (Fernandes, 2005). This has contributed to emerging markets becoming more liquid and informationally transparent, allowing for a higher degree of efficiency (Lesmond, 2005; Yang and Pangastuti, 2016; Debata, Dash, and Mahakhud, 2018). At the macroeconomic level, studies suggest that financial integration tends to improve financial infrastructure, since it improves the allocation of resources, enhancing both consumption and income risk sharing, and reduces the volatility of consumption growth (Islamaj, 2014; Rizvi, Arshad, and Alam, 2018).

The effects of increasing the integration and development of financial markets in emerging economies on their volatility and efficiency have been investigated and documented. However, we have little evidence of whether such effects a) express themselves over time under differing economic conditions or b) are exhibited differently over the short versus the long term. Different segments of investors in these markets behave differently (e.g. Kim and Wei, 2002), depending on their risk appetite and investment time horizons, and decomposing them therefore makes our analysis of interest to regulators. There has also been debate about the channels through which emerging stock markets exhibit changes in efficiency and volatility over time (Hull and McGroarty, 2014). Although several longitudinal studies have analysed the efficiency and volatility of emerging equity markets, very few have attempted to study the contemporaneous effects of market development and exogenous shocks on these two characteristics of the market together. It is also interesting to study changes in the volatility and efficiency of equity markets over time, since they reflect changes in the composition of market participants, institutions, and business conditions over time (Lim and Brooks, 2011).

Our study focuses on two major inquiries. First, it constitutes an interlinked exploration of volatility and efficiency in Asian emerging economies. Second, this study is an attempt to understand these parameters along two time horizons, decomposed for short- and long-term market components. Our study is important 
because we do not explore the validity of the efficient market hypothesis ${ }^{4}$ but, rather, focus on the variance in efficiency and volatility arising from the linkage between stock markets and economic growth. Since the mid-1980s, most emerging countries opted to liberalize their financial markets. Most of the related academic literature has focused on testing the informational efficiency of developed markets (See: Henry, 2000; Kim and Singal, 2000; Chordia, Roll, and Subramanyam, 2005; and Abiad, Daniel, and Ashoka, 2009) rather than that of emerging markets (e.g. Bekaert, Harvey, and Lundbald, 2007; Guidi and Gupta, 2011; and Rizvi et al., 2018).

Research in Asian emerging markets on the efficiency and volatility of equity markets is particularly limited. Guidi and Gupta (2011) reject the efficient market hypothesis for the stock markets of Indonesia and Malaysia. This conclusion is also reached by Faiq, Xinping, Shahid, and Usman (2010).

Worthington and Higgs (2006) examine the weak form efficiency of 10 emerging and five developed markets in Asia using serial correlation coefficient and runs tests but find no evidence of random walk behaviour in the emerging market stocks (in China, India, Indonesia, Korea, Malaysia, Pakistan, the Philippines, Sri Lanka, Taiwan, and Thailand), which were thus characterized by inefficiency. A similar study by Claessens, Dasgupta, and Glen (1995) tested for return anomalies and predictability using the Lo-MacKinlay statistic and several other statistical methodologies, finding 20 emerging stock markets to be inefficient. Hoque et al. (2007) examine the weak form efficiency of eight emerging Asian stock markets before and after the Asian crisis, employing two new variance ratio tests, that is, Wright's rank and sign and Whang-Kim subsampling tests, as well the LoMacKinlay and Chow-Denning tests. They find no significant effect on the degree of efficiency. Six of the markets (Hong Kong, Indonesia, Malaysia, the Philippines, Singapore, and Thailand) remained inefficient even after the Asian crisis. On a similar note, Kim and Shamsuddin (2008), using multiple variance ratio tests based on the wild bootstrap and signs, find no significant change in efficiency associated with the impact of the Asian financial crisis. The objective of our study is to explore the linkages between the characteristics of stock markets and economic growth, dissecting these characteristics into the short and long term.

To achieve the above-mentioned objective, a three-step process is employed. First, we employ wavelet decomposition to decompose the daily return series into timescales, to distinguish between short and long term. Second, EGARCH model is used to calculate the volatility of the return series in different economic cycles. Third, we employ multifractal detrended fluctuation analysis (MFDFA) to explore the efficiency of the markets during different economic times.

Our findings can be divided into two distinct streams. First, in terms of the exploration of the volatility of Asian emerging economies, we conclude there is evidence of relatively higher volatility, with lower volatility in the shorter term,

\footnotetext{
${ }^{4}$ An efficient market ensures that all parties are privy to the same information and risks, allowing for optimal resource allocation, which, in turn, increases economic growth (Laopodis, 2004; Griffin, Kelly and Nardari, 2010). Bekaert and Harvey (1998) suggest that informational efficiency is essential to the connection tying stock markets to economic growth in emerging economies.
} 
for countries that experienced liberalization and fast-paced economic growth. We extend the literature on the business cycle and its linkage to stock market efficiency to a dual horizon, since earlier studies have only explored a single-horizon linkage between business cycle and stock market efficiency (Fama, 1990; Binswanger, 2000; Siliverstovs and Duong, 2006; Antonios, 2010). Second, our study extends the literature on stock market efficiency and volatility in a multifractal environment by delving deeper into Asian emerging markets. Earlier works by Rizvi, Dewandaru, Bacha, and Masih (2014), Arshad and Rizvi (2015), Rizvi and Arshad (2016), and Alam, Arshad, and Rizvi (2016), for example, primarily focus on larger sample and developed market data and not on geographic regions. Our findings suggest that in earlier phases of sample periods highlighted by liberalization policies correspond with greater market efficiency in the long term.

The remainder of the paper is structured as follows. Following the introduction, Section II explores the data and sample countries. This is followed by a brief discussion of the methodology in Section III. Section IV explores the empirical results. Concluding remarks and policy implications are presented in Section V.

\section{DATA AND SAMPLE COUNTRIES}

Our data set is comprised of eight stock markets from Asia Pacific emerging economies. ${ }^{5}$ The classification of emerging economies is obtained from the Morgan Stanley Composite Indices comprising measurements of economic development, size, and liquidity, as well as market accessibility. The sample period runs from 1 January 2001 to 31 December 2017 for the benchmark indices, sourced from Datastream. ${ }^{6}$ Daily returns are calculated using the equation $r_{t}=\ln \left(P_{t}\right)-\ln \left(P_{t-1}\right)$, where $r_{t}$ and $P_{t}$ denote the daily return and price on business day $t$, respectively.

The sample countries are China, India, Indonesia, Malaysia, the Philippines, South Korea, Taiwan, and Thailand. For a robust understanding of the behaviour of efficiency and volatility of these emerging markets, we divide the data into three periods to factor in different phases the world markets have gone through in the sample period. The initial period, from 2001 to 2002, is when markets in developed countries underwent turmoil in the aftermath of corporate scandals such as Enron and WorldCom, in addition to the September 2001 World Trade Centre attacks, all of which had a significant impact on our sample countries. After 2002 until 2006, the global economy experienced a normal phase of steady economic growth, with no major financial or economic crises. This period is classified as the normal boom period and lasts from 2003 to 2006. After the normal period until 2017 is classified as the crisis period, beginning with the US financial sector crisis turning into a global economic slowdown followed by the euro crises. Table 1 provides an overview of the descriptive statistics of the sample markets.

\footnotetext{
5 We use the MSCI broad market indices for China, India, Indonesia, Malaysia, Philippines, South Korea, Taiwan, and Thailand.

6 Since the classification of emerging markets changes regularly, January 2001 onwards is the common period for our sample indices.
} 
Table 1.

Descriptive Statistics

This table details the key economic statistics for the whole sample period of 2001-2017. The first indicator is the GDP growth. The second indicator is market size/GDP. This represents the average market capitalization as a ratio of real GDP during the period. The third indicator is 'Liquidity', which represents the total turnover in the stock market. It is calculated as total value of shares traded as a ratio of market capitalization. The data for columns 2-4 have been obtained from the World Bank Database (the World Development Indicators). The last column shows the exchange rate regime that has been acquired from official International Monetary Fund classification of exchange rate Agreements.

\begin{tabular}{lcccc}
\hline & GDP Growth & Market Size/GDP & Liquidity & Currency \\
\hline Asia & $5.80 \%$ & $72.60 \%$ & $91.30 \%$ & \\
China & $10.00 \%$ & $62.80 \%$ & $134.60 \%$ & Floating \\
India & $7.20 \%$ & $66.60 \%$ & $102.40 \%$ & Floating \\
Indonesia & $5.50 \%$ & $33.40 \%$ & $48.30 \%$ & Floating \\
Malaysia & $4.80 \%$ & $139.70 \%$ & $31.00 \%$ & Floating \\
Philippines & $5.00 \%$ & $60.50 \%$ & $18.60 \%$ & Floating \\
Korea, Rep. & $4.10 \%$ & $74.40 \%$ & $213.40 \%$ & Floating \\
Thailand & $4.10 \%$ & $70.80 \%$ & $90.90 \%$ & Floating \\
\hline
\end{tabular}

\section{METHODOLOGY}

As discussed earlier, the methodology follows a three-step process, described in the following sections.

\section{A. Wavelet Decomposition}

We use wavelet analysis on the return series for every stock index to separate out the constituent multiresolution (multihorizon) components. To do so, we apply maximum overlap discrete wavelet transforms (MODWTs) to daily return series by sampling these at evenly spaced points in time. We transform the return series from the time domain to the scale (interval) domain to understand the frequency of the activity in the time series. We sample the daily return series at different scale crystals ( $j)$, as follows: $\mathrm{d}_{1}$ (2-4 days), $\mathrm{d}_{2}$ (4-8 days) days, $\mathrm{d}_{3}$ (8-16 days), $\mathrm{d}_{4}$ (16-32 days), $\mathrm{d}_{5}$ (32-64 days), and $\mathrm{s}_{5}$ (> 64 days). Application of wavelet decomposition has recently surged in the financial literature, since it allows one to capture the nonlinearity of financial time series data. Caetano and Yoneyama (2012), Arshad, Rizvi, Duasa, and Azmi (2014), Dewandaru, Bacha, Masih, and Masih (2014), Arshad and Rizvi (2015), and Aloui, Bacha, and Masih (2015) have explored the application of wavelet decomposition to answer questions related to stock market data. Most find wavelet decomposition to be a more reliable method, since it preserves the original properties of the stock market time series.

We use nondecimated orthogonal MODWT with symmlet 8 as a wavelet function to carry out a multiscale decomposition of the return series. The MODWT has the advantage of being flexible in terms of the length of data as well as being time invariant. The wavelet family symmlet 8 is chosen since it has the lowest level 
of asymmetry, which is more appropriate for financial series. The transformed return series $r(t)$ is represented as a linear combination of wavelet functions, as follows:

$$
r(t) \approx \sum_{k} s_{j, k} \boldsymbol{\phi}_{j, k}(t)+\sum_{k} d_{j, k} \boldsymbol{\Psi}_{j, k}(t)+\sum_{k} d_{j-1, k} \boldsymbol{\Psi}_{j-1, k}(t)+\cdots \sum_{k} d_{1, k} \boldsymbol{\Psi}_{1, k}(t)
$$

Where $j$ is the number of scale crystals (intervals or frequencies), $k$ is the number of coefficients in the specified component, and $\varphi_{j, k}(t)$ and $\psi_{j, k}(t)$ are the father and mother orthogonal wavelet pair, respectively:

$$
\begin{aligned}
& \phi_{j, k}(t)=2^{-j / 2} \phi\left(\frac{t-2^{j} k}{2^{j}}\right) \text { for } j=1 \text { to } j \\
& \psi_{j, k}(t)=2^{-j / 2} \psi\left(\frac{t-2^{j} k}{2^{j}}\right) \text { for } j=j \text { to } 11
\end{aligned}
$$

We use the summation of the decomposed scales $d_{1}$ (2-4 days) and $d_{2}$ (4-8 days) to represent the short-term investor horizon and $d_{5}$ (32-64 days) and $s_{5}(>64$ days) to represent the long-term investor horizon.

\section{B. Exponential GARCH Volatility}

The finance literature has extensively used GARCH models to study the volatility of stock markets in terms of both simple and decomposed volatility. Hammoudeh and Choi (2007) used a univariate GARCH model under two volatility regimes with Markov switching to examine the volatility behaviour for the transitory and permanent components of each Gulf Cooperation Council stock market. In a later study, Yu and Hassan (2008) employ EGARCH models for Middle Eastern and North African countries to model their stock market volatility.

In our study, with an ordinary GARCH model, we can see that the conditional variance is allowed to depend on its past; however, this standard model has limitations, since it cannot include leveraging effects or allow for a direct response between the conditional variance and the conditional mean. Hence, in this study, we concentrate on the asymmetric GARCH model developed by Nelson (1991), the EGARCH model, which is better suited for volatilities. The EGARCH model allows for more stable routine optimization and no parameter constraints:

$$
\ln \sigma_{j, t}^{2}=\omega_{t}+\beta_{j} \ln \left(\sigma_{j, t-1)}^{2}+\gamma \frac{\varepsilon_{t-1}}{\sqrt{\sigma_{t-1}^{2}}}+\alpha\left[\frac{\left|\varepsilon_{t-1}\right|}{\sqrt{\sigma_{t-1}^{2}}}-\sqrt{\frac{2}{\pi}}\right]\right.
$$

where $\sigma_{j, t}^{2}$ denotes the conditional variance, since it is a one-period-ahead estimate of the variance calculated based on any past relevant information; $\omega_{t}$ represents a conditional density function; the $\alpha$ consideration represents a symmetric effect of the model, that is, the GARCH effect; $\beta$ measures the perseverance in conditional volatility irrespective of market movements; and the parameter $\gamma$ measures the leveraging effect. 


\section{MFDFA}

In the attempt to understand the efficiency of stock markets, we apply MFDFA to our original return series. The MFDFA is proficient at measuring efficiency, since it allows us to sequentially rank the individual efficiency of markets. Furthermore, it can determine the extent of inefficiency. Borrowing from Kantelhardt, Zschiengerm, Koscienly-Bunde, Havlin, Bunde, and Stanley (2002), we summarize the procedural details of MFDFA below.

First, the analysis begins with a correlated time series (signal) $\{u i, \mathrm{i}=1, \ldots, N\}$, where $N$ is the size of the series, and the corresponding profile is determined by integration

$$
d f Y(k)=\sum_{i=1}^{k}\left[u_{i}-(u)\right], \quad k=1, \ldots, N
$$

After the corresponding profile $Y(k)$ is created, it is further divided into nonoverlapping windows of equal length $s$. The record length of $\mathrm{s}$ does not need to be an exact multiple of the time scale $s$ and a short portion at the end of the profile will exist in most cases. To counter this problem, the same process is repeated starting from the other end, resulting in $2 \mathrm{Ns}$ windows.

To evaluate the local trend of each window $v=1, \ldots, 2 \mathrm{Ns}$, a least squares fit of the data is considered. The detrended time series is denoted $Y_{s}(i)$ and is calculated as the difference between the original time series and the fit, that is,

$$
Y_{s}(i)=Y\left[\left(v-N_{s}\right) s+1\right]-p_{v}(i)
$$

For $v=1, \ldots, N_{s}$ and

$$
Y_{s}(i)=Y\left[N-\left(v-N_{s}\right) s+1\right]-p_{v}(i)
$$

For $v=N s+1, \ldots, 2 N s$, where $p(i)$ is the fitting polynomial in the $v$ th window. Since the detrending of the time series is carried out by subtracting the fit from the profile, these methods differ in their ability to eliminate trends from the data. In $m$ th-order MFDFA, trends of order $m$ in the profile and of order $m-1$ in the original record are eliminated. Thus, a comparison of the results for different orders of MFDFA allows estimation of the polynomial trend in the time series. Since we use a polynomial fit of order three, we denote the algorithm MFDFA-3.

The variance for both of $2 \mathrm{~N}_{s}$ of the detrended time series $\mathrm{Y}_{s}(\mathrm{i})$ is evaluated by averaging all data points $i$ in the $v$ th window:

$$
F_{S}^{2}(v)=\frac{1}{s} \sum_{i=1}^{s}\left(Y_{s}(i)\right)^{2}
$$

The qth-order fluctuation function is obtained by averaging over all segments

$$
F_{q}(s)=\left\{\frac{1}{N_{s}} \sum_{v=1}^{N_{s}}\left[F_{s}^{2}(v)\right]^{q / 2}\right\}^{1 / q}
$$

The process is repeated by starting from the beginning and, starting from the end,

$$
F_{q}(s)=\left\{\frac{1}{N_{S}} \sum_{v=N_{S}+1}^{2 N_{S}}\left[F_{S}^{2}(v)\right]^{q / 2}\right\}^{1 / q}
$$


The order $q$ can take on any real value. For $q=0$, the value $h(0)$ cannot be determined directly because of the diverging exponent. Instead, a logarithmic average procedure has to be employed. For $q=2$, the standard detrended fluctuation analysis procedure is used.

Finally, the scaling behaviour of the fluctuation is determined by analysing $\log -\log$ plots of $F q(s)$ versus $s$ for each value of $q$. If the series $u_{i}$ are long-range correlated, $\mathrm{Fq}(\mathrm{s})$ increases for large values of $\mathrm{s}$ as a power law:

$$
F_{q}(s) \sim S^{h(q)}
$$

For a stationary time series, the profile defined in equation (1) will be fractional Brownian motion. Thus, $0<h(q=2)<1$ for these processes and $h(q=2)$ is identical to the Hurst parameter, H. On the contrary, if the original signal is fractional Brownian motion, the profile will be a sum of the fractional Brownian motions, so $h(q=2)>1$. In this scenario, the relation between the exponent $h(q=2)$ and $\mathrm{H}$ is $H=h(q=2)-1$. Thus, the exponent $(q)$ is usually known as the generalized Hurst exponent.

\section{EMPIRICAL RESULTS}

Our efficiency analysis starts by the identification of apparent crossovers for each curve of sample country for all periods in question. Figure 1 presents the graphs for two countries in the sample used for crossover identification. Following identification, we calculate the slope of the generalized Hurst exponents for the short and long term. With the variation of $\mathrm{q}$ from -4 to 4 , we can observe that the change in the generalized Hurst exponents of the two subseries depends on $\mathrm{q}$, providing evidence of the apparent multifractal nature of the market returns. To the best of our knowledge, not many papers have explored the efficiency of stock markets using MFDFA, except Rizvi et al. (2014), Cajuero, Gogas, and Tabak (2009), and Arshad and Rizvi (2015), with whose results we concur.

\section{Figure 1. The Curve of Fq(S) Versus S In Log-Log Plot for Korea (Left) and India (Right)}

The following graphs show the plot of $\log \mathrm{Fq}(\mathrm{s})$ versus $\log \mathrm{s}$ on $\mathrm{y}$-axis and $\mathrm{x}$-axis, respectively. This graph is plotted for Hurst exponents $\mathrm{h}(\mathrm{q})$ when $\mathrm{q}$ varies from -4 to 4 . For a detailed understanding of the mechanics behind this, please refer to Rizvi et al. 2014.
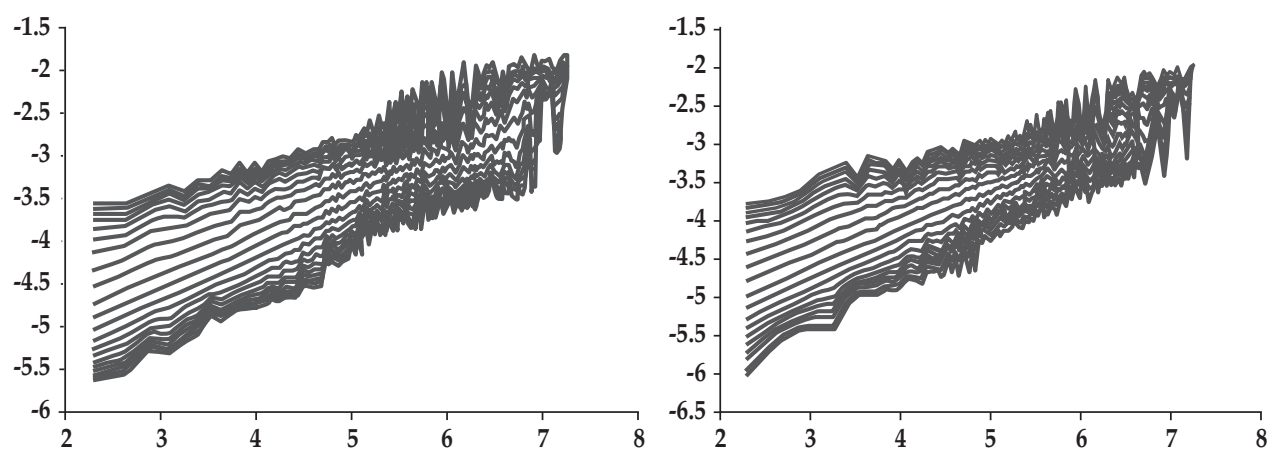
The multifractal analysis is conducted using $q=4$, considering the recent study of Jiang and Zhou (2007), who explore the determination of the apparent $q$ based on the divergence of the integrand for large values of $m_{a}$ (for a detailed discussion on the determination of q, see Zhou, Sornette, and Yuan, 2006; Jiang and Zhou, 2007; and Rizvi et al., 2014).

In line with earlier theory outlined in the literature review, for a market to be efficient, all fluctuations should follow a random walk. This translates into $h(q)$ associated with different values of q always being equal to 0.5. For our analysis, we focus on large and small fluctuations to define a market deficiency measure as follows:

$$
D=\frac{1}{2}(|h(-4)-0.5|+|h(4)-0.5|)
$$

Where the scale exponents $\mathrm{h}(4)$ and $\mathrm{h}(-4)$ are used to denote small and large price fluctuations, respectively. For a market to be efficient, the value of $D$ has to be close to zero, whereas a large efficiency value indicates a less efficient market. Since our focus is on the general efficiency of the market, the empirical analysis will focus on $D$ in both the short and long term.

Table 2.

\section{Efficiency Scores of Asian Emerging Market}

This table ranks countries according to their efficiency. The lower the efficiency value the more efficient the market. The efficiency measure is calculated using multifractal detrended fluctuation analysis MFDFA for the time period under consideration. The short-term horizon is the decomposed stock market return for less than 8 days, while long term horizon captures the decomposed stock returns for more than 32 days.

\begin{tabular}{llllll}
\hline \multicolumn{5}{c}{ Panel A: Full Sample 2001-2017 } \\
\hline Short term & & \multicolumn{5}{l}{ Long term } \\
\hline 1 & China & 0.129 & 1 & China & 0.025 \\
2 & India & 0.164 & 2 & India & 0.06 \\
3 & Indonesia & 0.177 & 3 & Indonesia & 0.079 \\
4 & Malaysia & 0.099 & 4 & Malaysia & 0.033 \\
5 & Philippines & 0.176 & 5 & Philippines & 0.065 \\
6 & South Korea & 0.134 & 6 & South Korea & 0.098 \\
7 & Taiwan & 0.114 & 7 & Taiwan & 0.105 \\
8 & Thailand & 0.135 & 8 & Thailand & 0.055 \\
\hline \multicolumn{5}{c}{ Panel B: 2001-2002 } \\
\hline Short term & Long term & \\
2 & & & 1 & China \\
3 & China & 0.113 & 2 & India & 0.026 \\
4 & India & 0.153 & 3 & Indonesia & 0.174 \\
5 & Indonesia & 0.317 & 4 & Malaysia & 0.169 \\
6 & Malaysia & 0.175 & 5 & Philippines & 0.211 \\
7 & Philippines & 0.214 & 6 & South Korea & 0.062 \\
8 & South Korea & 0.082 & 7 & Taiwan & 0.135 \\
\hline
\end{tabular}




\section{Table 2.}

Efficiency Scores of Asian Emerging Market (cont.)

This table ranks countries according to their efficiency. The lower the efficiency value the more efficient the market. The efficiency measure is calculated using multifractal detrended fluctuation analysis MFDFA for the time period under consideration. The short- term horizon is the decomposed stock market return for less than 8 days, while long term horizon captures the decomposed stock returns for more than 32 days.

\begin{tabular}{|c|c|c|c|c|c|}
\hline \multicolumn{6}{|c|}{ Panel C: 2003-2006 } \\
\hline \multicolumn{3}{|c|}{ Short term } & \multicolumn{3}{|c|}{ Long term } \\
\hline 1 & China & 0.095 & 1 & China & 0.02 \\
\hline 2 & India & 0.045 & 2 & India & 0.117 \\
\hline 3 & Indonesia & 0.188 & 3 & Indonesia & 0.129 \\
\hline 4 & Malaysia & 0.123 & 4 & Malaysia & 0.09 \\
\hline 5 & Philippines & 0.145 & 5 & Philippines & 0.149 \\
\hline 6 & South Korea & 0.07 & 6 & South Korea & 0.127 \\
\hline 7 & Taiwan & 0.109 & 7 & Taiwan & 0.029 \\
\hline 8 & Thailand & 0.112 & 8 & Thailand & 0.059 \\
\hline \multicolumn{6}{|c|}{ Panel D: 2007-2017 } \\
\hline \multicolumn{3}{|c|}{ Short term } & \multicolumn{3}{|c|}{ Long term } \\
\hline 1 & China & 0.151 & 1 & China & 0.035 \\
\hline 2 & India & 0.147 & 2 & India & 0.087 \\
\hline 3 & Indonesia & 0.153 & 3 & Indonesia & 0.069 \\
\hline 4 & Malaysia & 0.186 & 4 & Malaysia & 0.101 \\
\hline 5 & Philippines & 0.174 & 5 & Philippines & 0.064 \\
\hline 6 & South Korea & 0.239 & 6 & South Korea & 0.036 \\
\hline 7 & Taiwan & 0.174 & 7 & Taiwan & 0.066 \\
\hline 8 & Thailand & 0.135 & 8 & Thailand & 0.052 \\
\hline
\end{tabular}

Table 3.

Volatility Measure of Asian Emerging Market

This table provides the volatility measures across all countries. The values of volatility are the average EGARCH volatility measure. The short-term horizon factors in the decomposed stock market return for less than 8 days, while long term horizon captures the decomposed stock returns for more than 32 days.

\begin{tabular}{llllll}
\hline \multicolumn{5}{c}{ Panel A: Full Sample 2001-2017 } \\
\hline \multicolumn{5}{l}{ Short term } & \multicolumn{5}{c}{ Long term } \\
\hline 1 & China & $1.400 \%$ & 1 & China & $3.700 \%$ \\
2 & India & $1.180 \%$ & 2 & India & $3.360 \%$ \\
3 & Indonesia & $1.430 \%$ & 3 & Indonesia & $3.310 \%$ \\
4 & Malaysia & $0.690 \%$ & 4 & Malaysia & $2.070 \%$ \\
5 & Philippines & $1.200 \%$ & 5 & Philippines & $3.080 \%$ \\
6 & South Korea & $1.040 \%$ & 6 & South Korea & $3.160 \%$ \\
7 & Taiwan & $0.820 \%$ & 7 & Taiwan & $3.060 \%$ \\
8 & Thailand & $1.220 \%$ & 8 & Thailand & $3.410 \%$ \\
\hline
\end{tabular}


Table 3.

\section{Volatility Measure of Asian Emerging Market (cont.)}

This table provides the volatility measures across all countries. The values of volatility are the average EGARCH volatility measure. The short-term horizon factors in the decomposed stock market return for less than 8 days, while long term horizon captures the decomposed stock returns for more than 32 days.

\begin{tabular}{|c|c|c|c|c|c|}
\hline \multicolumn{6}{|c|}{ Panel B: 2001-2002 } \\
\hline \multicolumn{3}{|c|}{ Short term } & \multicolumn{3}{|c|}{ Long term } \\
\hline 1 & China & $1.590 \%$ & 1 & China & $4.050 \%$ \\
\hline 2 & India & $1.170 \%$ & 2 & India & $3.370 \%$ \\
\hline 3 & Indonesia & $1.530 \%$ & 3 & Indonesia & $4.000 \%$ \\
\hline 4 & Malaysia & $0.890 \%$ & 4 & Malaysia & $2.730 \%$ \\
\hline 5 & Philippines & $1.230 \%$ & 5 & Philippines & $3.140 \%$ \\
\hline 6 & South Korea & $1.770 \%$ & 6 & South Korea & $4.470 \%$ \\
\hline 7 & Taiwan & $1.520 \%$ & 7 & Taiwan & $4.320 \%$ \\
\hline 8 & Thailand & $1.350 \%$ & 8 & Thailand & $4.040 \%$ \\
\hline \multicolumn{6}{|c|}{ Panel C: 2003-2006 } \\
\hline \multicolumn{3}{|c|}{ Short term } & \multicolumn{3}{|c|}{ Long term } \\
\hline 1 & China & $1.170 \%$ & 1 & China & $3.110 \%$ \\
\hline 2 & India & $1.070 \%$ & 2 & India & $2.930 \%$ \\
\hline 3 & Indonesia & $1.290 \%$ & 3 & Indonesia & $3.320 \%$ \\
\hline 4 & Malaysia & $0.610 \%$ & 4 & Malaysia & $1.810 \%$ \\
\hline 5 & Philippines & $1.050 \%$ & 5 & Philippines & $3.130 \%$ \\
\hline 6 & South Korea & $1.000 \%$ & 6 & South Korea & $2.770 \%$ \\
\hline 7 & Taiwan & $0.700 \%$ & 7 & Taiwan & $2.950 \%$ \\
\hline 8 & Thailand & $1.120 \%$ & 8 & Thailand & $3.130 \%$ \\
\hline \multicolumn{6}{|c|}{ Panel D: 2007-2017 } \\
\hline \multicolumn{3}{|c|}{ Short term } & \multicolumn{3}{|c|}{ Long term } \\
\hline 1 & China & $1.480 \%$ & 1 & China & $3.940 \%$ \\
\hline 2 & India & $1.240 \%$ & 2 & India & $3.600 \%$ \\
\hline 3 & Indonesia & $1.490 \%$ & 3 & Indonesia & $3.120 \%$ \\
\hline 4 & Malaysia & $0.690 \%$ & 4 & Malaysia & $2.040 \%$ \\
\hline 5 & Philippines & $1.270 \%$ & 5 & Philippines & $3.030 \%$ \\
\hline 6 & South Korea & $0.860 \%$ & 6 & South Korea & $3.030 \%$ \\
\hline 7 & Taiwan & $0.700 \%$ & 7 & Taiwan & $2.770 \%$ \\
\hline 8 & Thailand & $1.240 \%$ & 8 & Thailand & $3.410 \%$ \\
\hline
\end{tabular}

Tables 2 and 3 report the efficiency and volatility measures respectively for the full sample and subsamples. Highlights from the findings suggest that the markets' development stage plays a role in their relative volatility and efficiency, conforming to recent literature (Dewandaru et al., 2014; Rizvi et al., 2018). China stands out as one of the more efficient markets in longer fundamentals-based horizons with relatively higher volatility. This can be explained by the relative sizes and liquidity of Chinese markets, as well as China's stronger economic fundamentals. The longer-horizon efficiency ranking of fundamentals-based 
investor sentiment and foresight tends to be more efficient, but, at the same time, volatility will be higher, owing to more long-term investments, as suggested by Rizvi et al. (2018). In contrast, the shorter-horizon stock market component is susceptible to inefficiencies due to liquidity crunches and speculative bubbles.

Within our sample period, the early crisis of 2001-2002 and the following economic boom phase of 2003-2006 provide interesting considerations for efficiency ranking analysis regarding the relatively higher efficiency in the longer term for almost all the sample countries. This could be a direct result of the gradual spread of financial liberalization policies across Asian markets. Our findings reiterate those of Cajueiro et al. (2009), who state for Greece, that all spans of an economic upswing and financial liberalization policies result in greater efficiency, which leads them to argue that financial liberalization has a positive impact on market efficiency. Based on earlier literature and theoretical underpinnings, we believe that longer-term fundamentals valuation-based investment liquidity in the markets increases available funds, improving the efficiency of Asian markets, as also evident in global investment patterns, with 2003-2006 showing an influx of heavy portfolio investments in the Asian region.

The next time span, 2007-2017, which was marred by the global economic slowdown, provides findings for our Asian emerging markets that are in contrast with those of previous periods. The Chinese stock markets stand out among their emerging Asian counterparts by exhibiting higher efficiency rankings for both shorter and longer horizons. This is due to the neutrality of the Chinese market to the global financial crisis and its stronger domestic investor base; however, at the same time, volatility is enhanced, which could due to a contagion effect (Aloui, Aissa, and Nguyen, 2011; Diminitriou, Kenourguis, and Simos, 2013). The devastating financial crisis of 2007-2008 wiped out \$34.4 trillion of wealth globally by March $2009,{ }^{7}$ putting immense pressure on emerging stock markets. This led to global investment portfolios squeezing their exposures in emerging countries across Asia and Europe to fund their losses in developed markets (ING Investment Management reports having withdrawn US\$600 billion from emerging markets ${ }^{8}$ ). The contagion effect of the resulting liquidity crunch was primarily focused on shorter horizons. Our result confirms the earlier findings on efficiency in developed markets of Rizvi et al. (2014) and Arshad and Rizvi (2015), who suggest that crisis periods result in deteriorating efficiency. The effect of contagion has also been documented for Asian markets by Dewandaru et al. (2014) and Rizvi, Arshad and Alam (2015), who argue the existence of pure contagion from the United States to the Asia Pacific markets. This evidence of pure contagion suggests that the impact of the financial crisis can be exacerbated in shorter horizons. Our findings suggest that efficiency and volatility performance worsens for all our sample emerging Asian markets. In terms of efficiency scores, we witness a significant decline in the shorter horizon for every recession compared to its preceding boom phase however, at the same time, these markets seem neutral to the crisis effect on longerhorizon efficiency and volatility. These findings have their underpinnings in the theory of liquidity and efficiency discussed by Chordia et al. (2008).

\footnotetext{
7 Roosevelt Institute, The Crisis of Wealth Destruction, 04-07-2010.

8 See https://www.ft.com/content/cd212164-f429-11e4-bd16-00144feab7de.
} 


\section{CONCLUSION}

Our investigation of emerging Asian stock markets provides interesting insights that can be explained through the structural aspect of these economies. Our findings suggest that liberalization policies in earlier phases of the sample period lead to the higher efficiency and variable volatility of the markets in the longer term. This argument could be introduced, with caution, in favour of the liberalization of capital markets to achieve the efficiency and stability of fundamentals. However, this also exposes markets to partial liquidation by foreign investors in crisis periods, creating inefficiencies in shorter horizons, according to the pure contagion argument.

These findings have key implications for regulators and global investors in terms of investment strategies. Our research furthers the literature on the efficiency and volatility of emerging Asian stock markets on a bi-horizon basis.

For economic managers and investors, the study suggests that emerging markets pursuing liberalization and economic fundamentals-based global integration are less volatile and relatively more efficient. The financial literature has, for years, highlighted that efficient stock markets assist in development of the economy, via resource allocation and capital formation, and in the distribution of wealth channels. Arguing in favour of investment in Asian emerging markets, our results suggest that these markets could be attractive for portfolio diversification in neutralization in shorter horizons.

While the findings provide interesting insights for investors and economic managers, they put policymakers in a difficult position. While liberalization policies lead to more efficient stock markets in longer horizons, they also increase susceptibility to international portfolio fluctuations, which the country has no control over, thus affecting market volatility. Sudden fluctuations in foreign investment portfolio flows can impact currency exchange rates, leading to other economic issues. However, primarily for sustainability, policymakers need to address the concerns of investors focused on the long term and move towards structural changes that govern their investment behaviour.

\section{REFERENCES}

Abiad, A., Daniel L. H., and Ashoka M. (2009). Financial Integration, Capital Mobility, and Income Convergence. Economic Policy, 24, 241-305.

Alam, N., Arshad, S., and Rizvi, S.A.R. (2016). Do Islamic Stock Indices Perform Better Than Conventional Counterparts? An Empirical Investigation of Sectoral Efficiency. Review of Financial Economics, 31, 108-114.

Aloui, R., Aïssa, M.S.B., and Nguyen, D.K. (2011). Global Financial Crisis, Extreme Interdependences, and Contagion Effects: The Role of Economic Structure? J. Bank. Finance, 35, 130-141

Arshad, S., Rizvi, S.A.R., and Ibrahim, M.H. (2014). Tripartite Analysis Across Business Cycles in Turkey: A Multi-Timescale Inquiry of Efficiency, Volatility and Integration. Borsa Istanbul Review, 14, 224-235.

Arshad, S., and Rizvi, S.A.R. (2015). The Troika of Business Cycle, Efficiency and Volatility: An East Asian Perspective. Physica A: Statistical Mechanics and its Applications, 419, 158-170. 
Arshad, S., and Rizvi, S.A.R. (2015). The Troika of Business Cycle, Efficiency and Volatility: An East Asian Perspective. Physica A: Statistical Mechanics and its Applications, 419, 158-170.

Atje, R., and Boyan, J. (1993). Stock Markets and Development. European Economic Review 37, 632-640.

Beck, T., and Levine, R. (2005). Legal Institutions and Financial Development. In: Menard, C., Shirley, M. (Eds.), Handbook for New Institutional Economics. Kluwer Academic Publishers, Norwell, MA.

Bekaert, G., and Harvey, C.R. (1998). Capital Markets: An Engine for Economic Growth. Brown Journal of World Affairs, 5, 33-58.

Bekaert, G., Harvey, C.R., and Lundblad, C. (2007). Liquidity and Expected Returns: Lessons from Emerging Markets. Review of Financial Studies, 20, 17831831.

Bell, C., and Rousseau, P.L. (2001). Post-Independence India: A Case of FinanceLed Industrialization. Journal of Development Economics, 65, 153-175.

Cajueiro, D.O., Gogas, P., and Tabak, B.M. (2009). Does Financial Market Liberalization Increase the Degree of Market Efficiency? The Case of the Athens Stock Exchange. International Review of Financial Analysis, 18, 50-57.

Campos, N.F., Karanasos, M.G., and Tan, B. (2012). Two to Tangle: Financial Development, Political Instability and Economic Growth in Argentina. Journal of Banking and Finance, 36, 290-304.

Caporale, G.M., Howells, P.G.A., and Soliman, A.M. (2004). Stock Market Development and Economic Growth: The Causal Linkage. Journal of Economic Development, 29.

Chordia, T., Roll, R., and Subrahmanyam, A. (2008). Liquidity and Market Efficiency. Journal of Financial Economics, 87, 249-268.

Claessens, S., Dasgupta, S., and Glen, J. (1995). Return Behaviour in Emerging Stock Market. The World Bank Economic Review, 9, 131-151.

Debata, B., S. R. Dash, and J. Mahakud. (2017). Investor Sentiment and Emerging Stock Market Liquidity. Finance Research Letters, 26, 15-31.

Dewandaru, G., Rizvi, S.A.R., Masih, R., Masih, M., and Alhabshi, S.O. (2014). What Factors Explains Stock Market Retardations In Islamic Countries? Emerging market Review, 19, 106-127.

Dimitriou, D., Kenourgios, D., and Simos, T. (2013). Global Financial Crisis and Emerging Stock Market Contagion: A Multivariate FIAPARCH-DCC Approach. International Review of Financial Analysis, 30, 46-56.

Faiq, M, Xinping, X., Shahid, H., and Usman, M. (2010). Chinese Stock Market Efficiency. Asian Journal of Management Research, 1, 268-282.

Ferdandes, N. (2005). Portfolio Disaggregation in Emerging Market Investments. Journal of Portfolio Management, winter, 41-49.

Griffin, J.M., Kelly, P., and Nardari F. (2010). Do Market Efficiency Measures Yield Correct Inferences? A Comparison of Developed and Emerging Markets. The Review of Financial Studies, 23, 3225-3277.

Guidi, F., and Gupta, R. (2011). Are ASEAN Stock Market Efficient? Evidence from Univariate and Multivariate Variance Ratio Tests. Discussion Papers in Finance: 201113, Griffith University. 
Guo, F., Huang, Y.S. (2010). Does "Hot Money" Drive China's Real Estate and Stock Markets? International Review of Economics E Finance, 19, 452-466.

Hammoudeh, S., and Choi, K. (2007). Characteristics of Permanent and Transitory Returns in Oil-Sensitive Emerging Stock Markets: The Case of the GCC Countries. International Review of Economics and Finance, 17, 231-245

Henry, P.B. (2000). Stock Market Liberalization, Economic Reform, and Emerging Market Equity Prices. Journal of Finance, 55, 529-564.

Hoque H., Jae H.K., and C.S. Pyun. (2007). A Comparison of Variance Ratio Tests of Random Walk: A Case of Asian Emerging Stock Markets. International Review of Economics and Finance, 16, 488-502.

Hull, M., and McGroarty, F. (2014). Do Emerging Markets Become More Efficient as They Develop? Long Memory Persistence in Equity Indices. Emerging Markets Review, 18, 45-61.

Islamaj, E. (2014). Industrial Specialization, Financial Integration and International Consumption Risk Sharing. The B.E. Journal of Macroeconomics- Contributions.

Jiang, Z-Q, and Zhou, W-Z. (2010). Complex Stock Trading Network Among Investors. Physica A, 389, 4929-4941.

Kantelhardt, J. W., Zschiengerm, S. A., Koscienly-Bunde, E., Havlin, S., Bunde, A., and Stanley, H. E. (2002). Multifractal Detrended Fluctuation Analysis of Nonstationary Time Series. Physica A, 316, 87-114.

Kim, E. Han, and Vijay Singal. (2000). Stock Market Openings: Experience of Emerging Economies. Journal of Business, 73, 25-66.

Kim, J.H., and Shamsuddin, A. (2008). Are Asian Stock Markets Efficient? Evidence from New Multiple Variance Ratio Tests. Journal of Empirical Finance 15, 518532.

Kim, W., and Wei, S. J. (2002). Foreign Portfolio Investors Before and During A Crisis. Journal of International Economics, 56, 77-96.

Lesmond, D.A. (2005). Liquidity of Emerging Markets. J. Financial Econ, 77, 411452.

Levine, R., and Zervos, S. (1993). What We Have Learned About Policy and Growth From Cross-Country Regressions. American Economic Review, 83, 426-430.

Lim, K. P., and Brooks, R. (2011). The Evolution of Stock Market Efficiency Over Time: A Survey of the Empirical Literature. Journal of Economic Surveys, 25, 69-108.

Luintel, K.B., and Khan, M. (1999). A Quantitative Reassessment of the FinanceGrowth Nexus: Evidence from A Multivariate VAR. Journal of Development Economics, 60, 381-405.

McKinnon, R. (2013). The Unloved Dollar Standard: From Bretton Woods to the Rise of the [People's Republic of] China. Oxford, UK: Oxford University Press.

Menkhoff, L., Sarno, L., Schmeling, M., and Schrimpf. A., (2012). Currency Momentum Strategies. Journal of Financial Economics, 106, 660-684.

Mishra, S., and Narayan, P.K. (2015). A Nonparametric Model of Financial System and Economic Growth. International Review of Economics and Finance, 39, 175191.

Narayan, P.K., and Narayan, S. (2013). The Short-Run Relationship Between the Financial System and Economic Growth: New Evidence from Regional Panels. International Review of Financial Analysis, 29, 70-78. 
Nelson, D. B. (1991). Conditional Heteroskedasticity in Asset Returns: A New Approach. Econometrica, 59, 347-370.

Rizvi, S.A.R., Arshad, S., and Alam, N. (2015). Crises and Contagion in Asia Pacific - Islamic V/S Conventional Markets. Pacific-Basin Finance Journal, 34, 315-326.

Rizvi, S.A.R., Arshad, S., and Alam, N. (2015). A Tripartite Inquiry Into VolatilityEfficiency-Integration Nexus - Case of Emerging Markets. Emerging Market Review, 34, 143-161.

Rizvi, S.A.R., Dewandaru, G., Bacha, O.I., and Masih, M. (2014). An Analysis of Stock Market Efficiency: Developed vs Islamic Stock Markets Using MF-DFA. Physica A: Statistical Mechanics and its Applications 407, 86-99.

Rizvi, S.A.R., Dewandaru, G., Bacha, O.I., and Masih, M. (2014). An Analysis of Stock Market Efficiency: Developed vs Islamic Stock Markets Using MF-DFA. Physica A: Statistical Mechanics and its Applications 407, 86-99.

Rousseau, P. L., and Wachtel, P. (2000). Equity Markets and Growth: CrossCountry Evidence on Timing and Outcomes, 1980-1995. Journal of Banking $\mathcal{E}$ Finance, 24, 1933-1957.

Zhou, W.-X., Sornette, D., and Yuan W.-K. (2006). Inverse Statistics and Multifractality of Exit Distances in 3D Fully Developed Turbulence. Physica $D, 214,55-62$.

Yang, A.S., and Pangastuti, A. (2016). Stock Market Efficiency and Liquidity: The Indonesia Stock Exchange Merger. Research in International Business and Finance, 36, 28-40. 